\title{
Tratamento Fora de Domicílio (TFD): uma abordagem sobre os desafios e perspectivas dos beneficiários do município de Macapá
}

\section{Treatment Outside the Home (TFD): an approach on the challenges and perspectives of the beneficiaries of the municipality of Macapá}

\author{
Daniele Ramos Guedes ${ }^{1}$, Fernanda Picanço Pimentel ${ }^{2}$, Geane Trindade Pereira ${ }^{3}$, Josicleia da \\ Conceição Marques ${ }^{4}$
}

${ }^{1}$ Bacharel em Serviço Social, Especialização em Gestão e Docência do Ensino Superior e Práticas Pedagógicas em Educação Especial, Mestranda do Curso em Saúde Pública pelo Instituto Ideia, docente Instituto Macapaense de Melhor Ensino Superior -IMMES e Assistente Social na área da Saúde no Munícipio de Ferreira Gomes, Amapá, Brasil. https://orcid.org/0000-0001-6608-2289 E-mail: danieleguedes.ap@gmail.com *Autor de correspondência

${ }^{2}$ Graduanda Bacharel em Serviço Social pelo Instituto Macapaense de Melhor Ensino Superior -IMMES, Macapá, Amapá, Brasil https://orcid.org/0000-0001-8166-2310 E-mail: nandapicanco31@gmail.com

${ }_{3}^{3}$ Graduanda Bacharel em Serviço Social pelo Instituto Macapaense de Melhor Ensino Superior -IMMES, Macapá, Amapá, Brasil. https://orcid.org/0000-0002-4325-8859 E-mail: geanetrindade26@gmail.com

${ }^{4}$ Graduanda Bacharel em Serviço Social pelo Instituto Macapaense de Melhor Ensino Superior -IMMES, Macapá, Amapá, Brasil. https://orcid.org/0000-0001-5881-6107 E-mail: josifap86@gmail.com

\section{Palavras-chave \\ Sistema Único de Saúde \\ Política de Saúde \\ Serviços Básicos de Saúde}

O Tratamento Fora de Domicílio-TFD, é um instrumento legal que visa garantir, pelo Sistema Único de Saúde SUS, o tratamento a pacientes portadores de doenças não tratáveis no município de origem. O benefício de Tratamento Fora de Domicílio - TFD consiste em fornecimento de passagens e ajuda de custo para deslocamento exclusivamente dos usuários do SUS. Diante disto, a presente pesquisa teve como objetivo geral abordar os desafios e perspectivas dos beneficiários do TFD do município de Macapá, de forma a expor o contexto social destas pessoas a partir desta garantia assistencial. Para isto, o desenvolvimento da pesquisa exploratória se deu através do levantamento bibliográfico e estudo de caso, no qual busca o aprofundamento de uma realidade especifica. Desta forma, esta pesquisa foi desenvolvida a partir de materiais publicados em livros, artigos, dissertações e teses e para coleta de dados teve como instrumento uma entrevista com roteiro semiestruturado, contendo cinco perguntas abertas, aplicadas aos pacientes/acompanhantes do TFD do município de Macapá que vivenciam os desafios impostos para se conseguir um tratamento mais adequado na rede pública. Portanto, conclui-se que o TFD é um direito do cidadão e um dever do Estado, de grande relevância a população usuária do SUS, tendo em vista que este é um dispositivo de cidadania e inclusão social. Assim, enfatiza-se a preocupação em se garantir as condições mínimas para que os pacientes e acompanhantes do TFD pelo município de Macapá, não excluindo desta os de outros municípios que compõem o Estado do Amapá, possam ter este direito garantido em todas as suas dimensões na oferta de um tratamento digno a quem dele necessita.

\section{Keywords}

Unified Health System Health Policy Basic Health Services

\begin{abstract}
Treatment Outside the Home - TFD, is a legal instrument that aims to guarantee, through the Unified Health System - SUS, the treatment of patients with untreatable diseases in the municipality of origin. The benefit of Treatment Outside the Home - TFD consists of providing tickets and travel allowance for travel exclusively by SUS users. In view of this, the present research had as general objective to approach the challenges and perspectives of the beneficiaries of the TFD of the municipality of Macapá, in order to expose the social context of these people from this assistance guarantee. For this, the development of exploratory research took place through a bibliographic survey and case study, in which it seeks to deepen a specific reality. In this way, this research was developed from materials published in books, articles, dissertations and theses and for data collection it had as an instrument an interview with a semi-structured script, containing five open questions, applied to the TFD patients / companions of the city of Macapá who experience the challenges imposed to achieve a more appropriate treatment in the public network. Therefore, it is concluded that the TFD is a citizen's right and a duty of the State, of great relevance to the SUS user population, considering that it is a device of citizenship and social inclusion. Thus, it is emphasized the concern to guarantee the minimum conditions so that the patients and companions of the TFD by the municipality of Macapá, not excluding from them the other municipalities that make up the State of Amapá, can have this right guaranteed in all its dimensions offering dignified treatment to those who need it.
\end{abstract}

\section{INTRODUÇÃO}

A República Federativa do Brasil, enquanto Estado
Democrático de Direito se fundamenta na garantia de elementos que favoreçam a plena cidadania e dignidade da população. Ao elencar nos seus caputs a garantia à saúde, 
como um dos direitos essenciais, básicos, traz para si a responsabilidade em prover a sua população mecanismos para sua efetivação. Vale ressaltar que esta garantia, enquanto direito, fora instituído a partir da Constituição de 1988 , pois anteriormente a ela não se tinha uma garantia de acesso à saúde, sendo ofertada somente aos trabalhadores contribuintes formais ou àqueles que dispunham de recursos financeiros.

Assim, a Constituição Federal de 1988 tratou especificamente no Título VIII da Ordem Social, Capítulo II da Seguridade Social, Seção II - da Saúde, conforme prevê o artigo no196 da CF/88: A saúde é direito de todos e dever do Estado, garantido mediante políticas sociais e econômicas que visem à redução do risco de doença e de outros agravos e ao acesso universal e igualitário às ações e serviços para sua promoção, proteção e recuperação (CONSTITUIÇÃO FEDERAL de 88, artigo 196).

Destarte, esta promoção da saúde envolve também elementos de ordem política, econômica e funcional que podem ocasionar em dificuldades para satisfazer as carências de saúde de grande parte dos cidadãos, pois podem ser elementos, que impedem uma organização de saúde que certifique serviços de boa qualidade que possa servir aos usuários em seu município de naturalidade. (AZEVEDO,2016)

Diante disto, Maciel (2016) manifesta que a integralidade e a equidade são os princípios que norteiam o Tratamento Fora do Domicílio, pois designa que o atendimento deva ser integral, isto é, as ações de saúde devem ser para a promoção, prevenção, recuperação e reabilitação do indivíduo e da comunidade, em qualquer nível de complexidade.

No entanto, Azevedo (2016) observou que o acesso universal e igualitário determinado como princípio do SUS vem sendo definido de maneira regressiva em decorrência da dificuldade advinda das enormes divergências regionais e da multiplicidade de contextos vivenciados pelos municípios do país. O Tratamento Fora de Domicílio-TFD, instituído pela portaria SAS/MS $n^{\circ}$ 55, de fevereiro de 1999 é um instrumento legal que visa garantir, pelo Sistema Único de Saúde - SUS, o tratamento a pacientes portadores de doenças não tratáveis no município de origem. O benefício de Tratamento Fora de Domicílio - TFD consiste em fornecimento de passagens e ajuda de custo para deslocamento exclusivamente dos usuários do Sistema Único de Saúde (SUS) e seus acompanhantes - se necessário para a realização de atendimento médico especializado em média e alta complexidade em Unidades de Saúde cadastradas e ou conveniadas ao SUS em outras Unidades da Federação (MACIEL, 2016).

Para Azevêdo (2016), a relevância do TFD torna-se mais evidente quando se atesta que muitos usuários do SUS não dispõem de condições financeiras para locomoverem-se dos municípios dos quais são domiciliados, tendo em vista a escassez das oportunidades para o tratamento apropriado do qual dependem para o progresso de sua saúde. Com isto, ressalta-se que este instrumento, em muitas situações, pode representar até mesmo a sobrevivência de muitos indivíduos.

Assim, compreende-se que esta ferramenta representa uma conexão entre o usuário do SUS e o prestador do serviço de saúde, no qual atua como um dispositivo de cidadania e inclusão social, e contribui para o eficaz funcionamento de outras políticas de saúde. Desta maneira, a presente pesquisa tem como objetivo geral abordar os desafios e perspectivas dos beneficiários do TFD do município de Macapá, de forma a expor o contexto social destas pessoas a partir desta garantia assistencial.

Com isto, o estudo justifica-se pela importância da temática, tendo em vista que o Tratamento Fora do Domicílio se inclui nos direitos concernente à saúde, pois, atende às demandas sociais, principalmente, no que se refere à deficiência dos serviços de saúde e a baixa condição econômica da maioria da população que não dispõe de recursos suficientes para financiar um tratamento na rede particular.

Almeja-se através desta pesquisa tornar visível os desafios vivenciados tanto pelos beneficiários do TFD quanto pelos acompanhantes para que os gestores públicos tanto da esfera Municipal, Estadual e Federal elaborem ações e estratégias que possa garantir um melhor amparo a estas pessoas.

\section{Tratamento Fora de Domicilio-TFD}

Um conjunto de ações do Estado no campo da saúde, introduziram significativas garantias aos cidadãos, principalmente a partir de mudanças advindas com a assistência à saúde e a criação do Sistema Único de Saúde (SUS). Foram desenvolvidos programas com vista a atender a população desde a atenção básica aos outros níveis e complexidades. E entre estes encontra-se o programa de Tratamento Fora do Domicílio. Que visa atender a população no fornecimento de passagens para atendimento médico especializado de diagnose, terapia ou cirurgia de alta complexidade, a ser prestado à pacientes atendidos exclusivamente pelo SUS, em outros municípios, além de ajuda de custo para alimentação e pernoite de paciente e acompanhante, se necessário (MACIEL, 2016).

Em consonância com Vieira e Nogueira (2017), corroborado que o TFD é um direito do cidadão e um dever do Estado, em conformidade com a Constituição Federal de 
1988 que garante o acesso universal e integral aos cuidados de saúde. A Portaria SAS/MS no 055 de 24/02/1999, dispõe sobre o TFD no âmbito do Sistema Único de Saúde, assegurando aos usuários desse sistema, o acesso ao transporte e a ajuda de custo, quando esgotados todos os meios de tratamento no município onde reside, desde que o local do atendimento esteja, a pelo menos, $50 \mathrm{~km}$ de distância. Oferece direito a acompanhante para crianças, adolescentes, pessoas com deficiência, idosos e àqueles que por sua condição de saúde não conseguem se deslocar sozinhos.

Portanto, Malbere et al (2015) evidencia que este programa visa atender aos usuários, garantindo-lhes a disponibilidade de consultas médicas e ambulatoriais; hospitalar e/ou cirúrgico antecipadamente agendados; o deslocamento de ida e volta para o local onde será realizado o tratamento e fornecimento de ajuda de custo para alimentação e hospedagem.

Assim, Maciel (2016) expõe que de acordo com a regulamentação do TFD o art 5o da Portaria MS no 055/1999 de 24/02/1999 criada pelo Ministério da Saúde estabelece que as Secretarias de Estado da Saúde devam propor estratégias de gestão do Tratamento Fora do Domicílio-TFD de acordo com a realidade de cada região, pois, de acordo com Almeida, Graciano e Dutka (2015), embora o TFD seja um direito, nem todos têm acesso devido à entraves burocráticos, organizacionais e até mesmo políticos.

Os critérios para concessão do Tratamento Fora do Domicílio - TFD são: laudo médico, exames complementares e solicitação do TFD. Para cada procedimento de alta complexidade são definidos critérios específicos e o atendimento precederá agendamento na unidade de referência (MACIEL, 2016).

\section{Desafios e perspectivas inerentes ao TFD}

As dificuldades enfrentadas pelos usuários no acesso e utilização do Programa se relacionam aos mais diversos aspectos sociais. Ainda que haja a existência do instrumento TFD de forma legal, os pacientes do SUS têm se deparado com adversidades para acessar ao programa, até mesmo os que precisam ter acompanhante como: mulheres com filhos internados, pacientes com doenças crônicas, entre outras circunstâncias. Assim, é explícito no contexto das unidades de saúde reivindicações referentes à ausência de condições financeiras dos pacientes e suas famílias. Desta maneira, é verificado que apesar da população ter direito à saúde integral, estes direitos têm rescindido como responsabilidades exclusivas desses indivíduos, no qual adversa a proteção dos direitos sociais largamente (NASCIMENTO; FERREIRA, 2016).
Para Gomes e Alcantara (2018), faz-se necessário conhecer o itinerário terapêutico e a realidade de quem busca esse atendimento, considerando as dificuldades encontradas, bem como também compreender as necessidades das pessoas envolvidas. Pode-se mencionar, por exemplo os estudos sobre itinerários terapêuticos de pacientes em busca de atenção à saúde que por vezes, são distintos e não coincidem necessariamente com esquemas ou fluxos pré-determinados pelo sistema básico de saúde. Ainda convém ressaltar que o trajeto realizado de maneira inadequada pode projetar um diagnóstico tardio, diminuindo as chances de cura e aumentando os riscos de sequelas e óbito

Diante das informações postas, esta pesquisa busca apresentar os desafios e perspectivas dos beneficiários e/ou acompanhantes do TFD do município de Macapá, de forma a expor o contexto social destas pessoas a partir desta garantia assistencial. Ressalta-se que as questões ora apresentadas não se esgotam em sua totalidade, pois reconhecemos que os anseios, dificuldades são inúmeras em decorrência de termos, segundo Almeida $(2013$, p.6) um sistema Único de Saúde que apresenta barreiras desde o "problema da dificuldade de acesso aos serviços de saúde, de acolhimento e de atendimento no tempo adequado"..

\section{MATERIAL E MÉTODOS}

A organização aplicada para a composição do trabalho foi desenvolvida a partir da delimitação do tema a ser explorado, posteriormente foi realizada a escolha dos assuntos norteadores a compreensão do tema abordado. Diante disto foi disposta a revisão bibliográfica que serviu como base para o entendimento e desenvolvimento do trabalho.

Este desenvolvimento se deu a partir de um estudo de caso, no qual busca o aprofundamento de uma realidade específica, através do tipo de pesquisa exploratória buscando uma abordagem qualitativa, executada a partir da observação direta das atividades do grupo estudado com o objetivo de captar opiniões e interpretações que ocorre naquela realidade. Este tipo de pesquisa tem por objetivo proporcionar maior familiaridade com o objeto em estudo e a descrição a partir das abordagens dos sujeitos envolvidos e levantar hipóteses a respeito do problema evidenciado, fundamentando o conteúdo em questão.

A presente pesquisa teve como instrumento para coletas de dados uma entrevista com roteiro semiestruturado aberto, contendo cinco perguntas, sendo utilizado um iphone como suporte de gravação. Aplicado entre os dias 09 e 13 do mês de março de 2020, na Associação Amapaense 
de Apoio aos pacientes em tratamento fora de domicílio (ASPTFD), localizada na avenida Ernestino Borges, 186, bairro Julião Ramos, no município de Macapá-AP. Participaram da pesquisa cinco pessoas, sendo dois acompanhantes e três beneficiários do TFD.

Para exposição dos dados, optou-se em apresentá-los a partir de categorias, seguindo método de análise de conteúdo proposto por Bardin (2011). Os depoimentos em análise, foram apresentados seguindo uma ordem numérica, na qual a fala de cada entrevistado foi marcada por A1, A2 para os acompanhantes e P1, P2 e P3 para designar os pacientes do TFD, como forma de identificá-los e preservar sua identidade.

Ressaltamos que a equipe de pesquisa buscou executá-la seguindo as orientações previstas na Resolução 466/2012 e 510/16, do Conselho Nacional de Saúde, vinculado ao Ministério da Saúde, que versa sobre aspectos éticos quando o objeto da pesquisa são seres humanos. Foi lido e entregue a cada entrevistado um termo de consentimento livre e esclarecido, contendo além de outros aspectos os objetivos da pesquisa qualitativa.

\section{RESULTADOS E DISCUSSÃO}

Os recortes dos dados extraídos das entrevistas foram transcritos fielmente como na fala, visando apresentar a partir de cada categoria aspectos psicológicos de cada participante com relação aos desafios enfrentados e as aspirações, tendo como foco principal captar a realidade social desses beneficiários do município de Macapá. Assim, foram extraídas as colocações mais relevantes de acordo com cada categoria, sendo:

\section{O benefício TFD versus a manutenção do paciente durante o tratamento fora do domicílio}

Através desta categoria buscou-se identificar os desafios enfrentados pelos pacientes e acompanhantes sobre os aspectos das garantias básicas necessárias para se manter enquanto dependente da ajuda de custo ofertada pelo programa TFD, haja vista, a situação de vulnerabilidade econômica que muitos se encontram:

Infelizmente não. Primeiro que a gente nem sai com esse recurso, segundo é um valor insólito, porque se você vai pagar uma diária, alimentação, não dá nem para ficar um dia com esse valor que eles dão para ficar ajudando o beneficiário do TFD. A gente até entre nós brinca e questiona que no aeroporto, você já sai gastando $R \$ 80,00$ a $R \$ 100,00$ para duas pessoas, então não tem como $R \$ 49,50$ dá para me manter com meu filho lá fora. (A1)

Não supre nem $10 \%$ da necessidade a ajuda de custo do TFD. Se for viajar o paciente e o acompanhante é \$49,50 centavos a diária, o qual deveria viajar com o recurso e não viajamos. A gente viaja dois, três meses e hoje posso dizer quase um ano sem receber o recurso que era para você viajar em mãos, além do valor ser muito baixo, de acordo com a portaria ele é para minha alimentação com meu acompanhante, transporte e estadia. Como que vai dá? Numa cidade onde eu não fique em casa de apoio. (P1)

Não, não supre a necessidade, porque nosso gasto é bem maior, tem medicamentos, transporte e vários outros itens que acabamos gastando. A ajuda de custo era para se receber antes de viajar $e$ nunca sai, sai depois de dois, três meses. Meu filho viajou em agosto de 2019 e ainda não recebeu o lote dele, então não supre a necessidade. (A2)

Não, porque é muito gasto para você se deslocar para outro Estado, às vezes é nós quem compra medicamentos quando não tem. (P2)

Não, porque essa ajuda de custo, o certo é viajar com ele em mãos. Só que isso não está acontecendo, o que acontece é que passa mais de seis, sete meses para receber. Eu estou com seis viagem que não recebo esse valor. (P3)

Os dados obtidos nesta primeira categoria retratam a necessidade de ser oferecida pelo governo do Amapá uma ajusta de custo que possam suprir com as necessidades desses usuários, pois os valores que recebem para alimentação e, quando há necessidade de pernoite (para paciente e acompanhante), é um total de $\mathrm{R} \$ 49,50$ e de $\mathrm{R} \$ 24,75$ quando o paciente não possui acompanhante, sendo valores instituídos pelo Ministério da Saúde através da portaria $\mathrm{N}^{\circ} 2.488$, de outubro de 2007.

O que se verifica é uma ausência de normativa pelo 
Estado do Amapá, que regule prevendo as necessidades dos pacientes, inclusive com reajuste dos valores, para que não haja tanta discrepância entre os valores e o custo de vida do local de tratamento.

Outro ponto relevante é referente a disponibilidade dos recursos. Partindo dos relatos, evidencia-se o atraso no pagamento, o que ocasiona incertezas em relação a manutenção do tratamento. Dessa forma, é imperativa a necessidade da garantia prévia do auxílio com valor adequado afim de assegurar condições de dignidade ao beneficiário do recurso.

\section{A aprovação do TDF, tempo e contratempo}

Os dados apresentados a seguir referem-se à forma de acesso ao TFD e os possíveis entraves burocráticos que os pacientes podem ter vivenciados.

No meu caso com meu filho até que foi rápido, por ele ser menor porque eu tive todo o apoio da nefrologia. Como ele fazia hemodiálise e até então não sabia o que era o TFD, a doutora chegou até mim só preciso dos teus documentos e do seu filho, então ficou tudo na mão da assistente social da nefrologia e foi tudo rápido, mas hoje em dia a gente vê que não é assim que funciona o TFD. (A1)

No caso de meu filho foi de forma rápida. Eu trabalhava no HCAL como copeira, então tinha acesso à muitos setores, então para mim houve agilidade, porém na primeira consulta não tivemos êxito, pois houve dificuldade de transporte onde foi negada a passagem dele. (A2)

Houve uma demora, eu descobri em 4 de janeiro e apenas em março viajei, então houve uma demora, pois, o câncer não espera. (P2)

Quanto a esta categoria, pode-se observar que o processo para se obter o tratamento fora de domicílio transcorreu sem entraves para aqueles que de certa forma tiveram auxílio dos próprios profissionais da saúde e, outro caso, por estarem inseridos na rotina do setor hospitalar, conforme relata (A2). Segundo Viegas et al. (2015), o acesso aos serviços de saúde na dimensão do que o autor chama de "operacional", o que diz respeito a entrada do indivíduo nos serviços, é um dos obstáculos a efetividade do SUS e, para tanto, é preciso fomentar ações visando fortalecer a porta de entrada do sistema de saúde pública, na sua organização a partir das demandas tanto sanitárias quanto social, para que esse acesso ocorra de forma direta e igualitária no atendimento das necessidades da população, aumentando a satisfação na obtenção dos serviços e agilidade em sua prestação, haja vista a urgência de tratamento, conforme consta no depoimento (P2) quando menciona que "o câncer não espera".

\section{O impacto do tratamento com o auxílio na vida das pessoas}

Nesta categoria, buscou-se apresentar além das questões financeiras, mudanças na vida cotidiana tanto no campo subjetivo e emocional a que estão sujeitos os pacientes e acompanhantes.

Sim, tanto na forma financeira como na emocional, porque a gente sai da nossa zona de conforto para ir para outro estado que você nem sabe de como vai ser acolhido. Na época eu deixei minha filhinha que tinha cinco anos, perdi toda aquela fase de terminar o $A B C$ dela e começar o ensino fundamental porque a gente ficou um ano e oito meses em são Paulo no tratamento do meu filho. (A1)

Sim, quando adoeci minha filha caçula tinha quatro meses e o meu menino tinha cinco anos. Eu estava gestante da minha filha quando conheci uma pessoa maravilhosa, eu disse que não ia esperar minha filha nascer para procurar babá, então em dezembro essa senhora começou a trabalhar comigo e em janeiro minha filha nasceu. Digo que quando adoeci ela assumiu meus filhos e minha casa por três anos, hoje minha filha tem três anos $e$ chama ela de mãe e meu filho tem oito anos eu tive problemas com ele na escola, dele não querer ir, de ficar isolado, porque ele queria a mãe dele, então não foi fácil. (P1)

Sim, eu tenho outro filho menor e tive que deixar ele com pessoas estranhas, porque eu não tenho família aqui para me apoiar, isso acarretou o afastamento, perdi muita coisa do meu filho. Hoje estou com uma bebê e o TFD não disponibilizou que fosse na última consulta dele por eu estar no final da gestação.(A2)

Sim, por ser longe o meu tratamento, nem todos da minha família tinham condições de estar comigo, foi apenas minha irmã para ficar comigo, meus pais não 
acompanharam meu tratamento e é um momento em a gente quer está perto da família, fiquei muito debilitada. (P2)

Sim, porque deixamos para trás filho, marido, e a primeira vez que fui viajar passei seis meses. Hoje eu estou com doze anos de tratamento então eu perdi tudo.

O direito à saúde, previsto na Constituição Federal de 1988, enquanto direito fundamental, deve ser garantido de forma plena pelas três esferas de governo, visando a plena integridade da pessoa humana. Amaral (2009 apud ALMEIDA et al., 2019, p.45) descreve que "a lesão a esse direito causa o chamado danos à saúde ou biológico, que é um dano não patrimonial, em senso estrito, e moral, pelo objeto ou interesse que afeta". No entanto, os resultados dos dados nesta categoria mostraram que a ausência de tratamento no local de domicílio, perpassam além dos danos biológicos, sendo afetado também o emocional de quem precisa se deslocar para outras localidades em busca de saúde por falta de tratamento especializado no município de origem. A lei no 8.080, de 19/09/1990, que regula o Sistema Único de Saúde (SUS) prevê que é dever do Estado garantir as condições necessárias para a plena efetivação desse direito, porém, no Brasil o acesso a esses bens segundo Machado (2009 apud GURJÃO, MAIA, CARVALHO, 2018, p.160) “ainda se apresenta como desafio ao Projeto de Reforma Sanitária, bem como ao pleno funcionamento do SUS".

\section{Perspectivas sobre o TFD, como conquista de direito}

Estes dados apresentam as concepções dos usuários quanto ao conhecimento que se tem do TFD sob a ótica do direito enquanto garantia.

Não só acredito como tenho certeza. Mas só que infelizmente aqui no Estado não é isso que a gente vive, essa conquista de direito não está sendo assegurada. (A1)

Sim, se ele realmente funcionasse como manda a portaria, ele seria uma conquista maravilhosa. E que é direito é, se meu estado não tem, ele é obrigado a me mandar para fora. (P1)

Sim, é uma conquista pelo fato de não ter tratamento no local, então esse tratamento alternativo é muito importante.(A2)

Acho que sim, para nós que precisa desse meio para viajar, porque muita família não tem condições de arcar com viagens por ser muito caro aqui no estado não tem tratamento. (P2)

Eu creio que sim, porque se não fosse o TFD a gente ia ficar nesse Estado onde não tem recurso de nada. Por uma parte eles se viram pela a gente, por outra não. Eles dão passagem, casa de apoio quando tem vaga, quando não tem a gente tem que pagar hotel.(P3)

Nesta abordagem, os resultados mostraram que todos têm conhecimento do programa TFD como garantia de direito. No entanto, em análise mais profunda percebe-se que para estes usuários a garantia do TFD precisa não somente está previsto em legislações, mas na plena efetividade das ações que possam assegurar condições de dignidade nos tratamentos a que estes carecem, pois, segundo Costa e Sturza (2010. p.74) "O direito à existência digna não é assegurado apenas pela não abstenção do Estado em afetar a esfera patrimonial das pessoas sob a sua autoridade, mas passa também pelo cumprimento de prestações positivas". Isso significa que o Estado devem realizar ações que visam assegurar a proteção da saúde dos cidadãos, sejam mediantes políticas sociais ou econômicas, que venham a garantir serviços de promoção, proteção e recuperação da saúde, haja vista que a dignidade está relacionada com o respeito aos direitos fundamentais da pessoa.

\section{Aspectos apontados e que devem ser melhorados}

Os resultados expressam as perspectivas esperadas pelos pacientes e acompanhantes do programa TFD do município de Macapá.

Em vários aspectos, um deles a gente pode dizer tanto ter a estrutura física do TFD ser mais humanizado. Você recebe um diagnóstico e fala que você vai precisar de um tratamento fora de domicílio, e você fica, o que tem que fazer? Eles mandam você correr atrás de muita papelada, você consegue entregar essas papeladas e eles demoram muito para conseguir uma vaga para consulta lá fora, até processo nosso eles perdem, os técnicos que trabalham lá no TFD são muito grosseiros, não te orientam no que você tem direito, então eles precisam ter pessoas capacitadas. (A1) Se a gente viajasse com recursos em mãos. (P1)

Precisa ser melhorado muita coisa, porque hoje o TFD está pior do pior, pois criaram 
uma comissão que segundo o regimento do TFD, a comissão é para avaliar casos de novos processos que irão entrar e não os processos que já estão. Então ela está dificultando a vida dos usuários escolhendo quem vai viajar e quem não vai. Se nós estamos no programa é porque não tem tratamento aqui no Estado. (A2)

A ajuda financeira, porque é uma situação muito difícil e tem pessoas que não tem de onde tirar dinheiro, o medicamento de quem tem câncer é muito caro. (P2)

Eu creio que seja o dinheiro que tem que ser levado em mãos. Enem toda vez a gente tem recurso para levar, eu não tenho capital.(P3)

Os resultados desses dados mostram que muito mais da necessidade de garantia do TFD, exige-se a responsabilidade da gestão administrativa da saúde pelo Estado, pois o direito à saúde enquanto cláusula pétrea da Constituição Federal de 1988, exige a necessidade do poder público de prover a eficiência dos serviços públicos de forma a garantir condições dignas da pessoa humana, sob pena de responsabilidade (COSTA E STURZA, 2010). As condições para promoção, proteção e recuperação da saúde dispostas através da lei Orgânica da Saúde (LOS - 8.080/1990) devem ser o pilar das decisões governamentais em garantir a todos igualdade e oportunidade de tratamentos de saúde, sendo também relevante um olhar mais humanizado de todos os envolvidos na efetividade desse direito.

\section{CONCLUSÕES}

Levando em consideração os resultados da pesquisa, onde os usuários beneficiários contrapuseram suas percepções quanto a este tratamento, temos que, o funcionamento do programa é de grande importância para a saúde pública, no entanto, o mesmo precisa ser aplicado de acordo com o que é proposto em sua legislação, para garantir os direitos a saúde conforme o que preconiza a Constituição Federal de 88. No entanto, a garantia do TFD precisa não somente está previsto em legislações, mas na plena efetividade das ações que possam assegurar condições de dignidade nos tratamentos a que deste carecem. Esta efetividade perpassa para além de acompanhamento médico, exames laboratoriais. É preciso lançar um olhar mais humano sobre os pacientes, enquanto sujeitos de dignidade, garantindo-Ihes as condições necessárias com vista a atenuar os impactos sofridos, inclusive psicológico, em decorrência do deslocamento para outras localidades em busca de saúde por falta de tratamento especializado.

Percebe-se que o acesso à saúde engloba fatores de ordem política, econômica e funcional que podem resultar em dificuldades que impedem a satisfação das necessidades de assistência de grande parte da população, por tanto, é preciso um engajamento dos entes federativos, no cumprimento de suas responsabilidades, direcionando melhores investimentos na questão das necessidades básicas de saúde, posto que a saúde enquanto direito exige que o Estado preste serviços que venham proporcionar condições dignas de atendimento e tratamento, haja vista que a saúde não está relacionada somente a ausência de doenças, engloba também o bem-estar em três dimensões: físico, mental e social. Fernandes (2010) menciona que pelo princípio da integralidade e equidade do SUS, os gestores devem pactuar ações que possam favorecer estratégias através de planejamentos que estejam em conformidade com a necessidade de cada região, visando a distribuição igualitária e atenção integral dos serviços de saúde.

Desta forma, o conhecimento sobre o itinerário terapêutico dos pacientes em tratamento, possibilita a compreensão dos desafios postos quanto a estrutura do Sistema de Saúde, o acesso das famílias aos serviços. Assim, os resultados desta pesquisa devem ser evidenciados como uma preocupação, pois, deve-se garantir condições mínimas para que os pacientes e acompanhantes do TFD pelo município de Macapá, não excluindo desta os de outros municípios que compõem o Estado do Amapá, possam ter este direito garantido em todas as suas dimensões na oferta de um tratamento digno a quem dele necessita. A saúde, ora já mencionado, é um direito e é fundamental para o desempenho de outros direitos sociais, sendo imprescindível a adoção de medidas visando sua proteção e manutenção. Assim, há necessidade de ser oferecida pelo governo do Amapá auxílios com valores corrigidos para que não haja tanta discrepância entre os valores e o custo de vida do local de tratamento suprindo assim as necessidades dos usuários, amparo material e emocional aos pacientes e acompanhantes, e locação de recursos na área visando proporcionar atendimento especializado no próprio Estado.

\section{REFERÊNCIAS}

ALMEIDA, Talita Xavier; GRACIANO, Maria Inês Gândara; DUTKA, Jeniffer de Cássia Rillo. Caracterização social e demográfica de usuários de prótese de palato e recursos de apoio à reabilitação. RIPE - Revista do Instituto de Pesquisas e Estudos: Construindo o Serviço Social, Bauru, v.19, n. 35, p. 307-329, jan. /jun.2015.

ALMEIDA, Rosângela Nunes; FILHA, Francidalma Soares 
Sousa Carvalho; MOREIRA, Alison de Sousa; SILVA, Maria Lindalva Alves; SANTOS, Elzimar Palhano; PAIVA, Lívia Cristina da Silva; MACEDO, Lawanda Kelly Matias. Atenção à mulher no pré-natal: Análise da assistência versus direito à saúde. Revista Arquivos Científicos (IMMES). Macapá, AP, Ano 2019, v. 2, n. 2, p. 41- 4. Disponível

em:http://arqcientificosimmes.emnuvens.com.br/abi/arti cle/view/131/79. Acesso em: 27 fev. 2020.

AZEVÊDO, Sandro Roberto. O programa de tratamento fora de domicílio no sistema único de saúde no Piauí. Holos, [S.I.], v. 2, p. 402-413, abr. 2016. ISSN 1807-1600. Disponível

em: <http://www2.ifrn.edu.br/ojs/index.php/HOLOS/article/v iew/3360/1457>. Acesso em: 27 fev. 2020.

BARDIN, L. Análise de conteúdo; tradução Luís Antero Reto; Augusto Pinheiro. São Paulo: Ed. 70, 2011.

BRASIL. Constituição Federal de 1988. Promulgada em 5 de outubro de $1988 . \quad$ Disponível em <http://www.planalto.gov.br/ccivil_03/constituicao/const ituição.htm>. Acesso em: 29 fev. 2020.

COSTA, Marli Marlene Moraes. STURZA, Janaína Machado. O direito à saúde enquanto elemento fundamental da dignidade humana: pressupostos de efetividade $e$ exigibilidade. Revista do Curso de Direito da FSG, Caxias do Sul, ano 4, n. 7, jan./jun. 2010, p. 71-83. . Disponível em: http://ojs.fsg.br/index.php/direito/article/view/598. Acesso em: 29 fev. 2020.

FERNANDES, S.D.P.Tratamento Fora de Domicílio no Quarto e Sétimo Centros Regionais de Saúde do Estado do Pará: informações úteis para o planejamento da gestão do trabalho do SUS. 2010. Dissertação (Mestrado PROFISSIONAL EM Saúde e Gestão do trabalho) Universidade do Vale do Itajaí-UNIVALI, Itajaí, p. 41, 2010.

Disponível em:http://siaibib01.univali.br/pdf/Silvio\%20Darley\%20Pe reira\%20Fernandes.pdf. Acesso em 20 mar. 2020.

GOMES, Brenda; ALCANTARA, Luciana. Dos sintomas ao tratamento: considerações sobre o itinerário terapêutico no câncer infanto-juvenil. Revista de Serviço Social UNIGRANRIO, vol. 1, N.2, 2018.

GERHARDT T.E. Itinerários terapêuticos em situações de pobreza: diversidade e pluralidade. Cadernos Saúde Pública. 22(11):2449-63. 2006.

HUESCA, Isabel Marco; VARGAS, Eliane Portes; CRUZ, Marly Marques da. Proteção social brasileira e demandas no tratamento oncológico infantojuvenil. Ciência \& Saúde Coletiva [online]. 2018, v. 23, n. 11, pp. 3965-3978. Disponível em: https://doi.org/10.1590/1413812320182311.26932016. ISSN 1678-4561. Acesso em: 27 fev. 2020.
LOPES, Analu dos Santos; SILVA, Débora Cristina da; GRAMS, Nathalia; BURLIN, Andreia. Intervenção do assistente social junto ao núcleo de transplante hepático do HU/UFSC. II Seminário Nacional de Serviço Social, Trabalho e Política Social, 2017. Disponível em: https://repositorio.ufsc.br/xmlui/bitstream/handle/1234 56789/180183/102 00454.pdf?sequence=1\&isAllowed=y . Acesso em 28 fev. 2020.

MACIEL, Danielle. TFD- Tratamento fora do domicilio no município de Santana do Livramento estado do Rio Grande Do Sul. 47 p. Trabalho de Conclusão de Curso (Graduação) - Universidade Federal do Pampa, administração, 2016 Disponível em: https://dspace.unipampa.edu.br/bitstream/riu/1783/1/D anielle\%20Lopez\%20Maciel.pdf. Acesso em 28 fev. 2020.

MALERBI, Fernando Korn et al. Doenças retinianas em um centro de referência de capital estadual na Amazônia Ocidental. Einstein (São Paulo), São Paulo, v. 13, n. 4, p. 530-534, dez. 2015.2 Disponível em: http://www.scielo.br/scielo.php?pid=S1679$45082015000400530 \&$ script $=$ sci arttext\&tlng=pt. Acesso em 28 fev. 2020.

NASCIMENTO, Bruna Maria de Sousa do; FERREIRA, Edley Juliana Menezes. Problematizações acerca da saúde da mulher: principais entraves e desafios para a consolidação dos direitos sociais. II Congresso de assistentes sociais do Estado do Rio de Janeiro, 2016. Disponível em: http://www.cressrj.org.br/site/wpcontent/uploads/2016/05/039.pdf. Acesso em 03 mar. 2020.

SANTOS, Brenda Gomes dos; ALCÂNTARA, Luciana da Silva. Itinerário terapêutico e Serviço Social: a trajetória de crianças e adolescentes com câncer. In: INCA. Diálogos em Saúde Pública e Serviço Social: a experiência do assistente social em oncologia. Instituto Nacional de Câncer José Alencar Gomes da Silva. - 2. Ed. Rio de Janeiro: Inca, 2018. Disponível em:https://www.inca.gov.br/sites/ufu.sti.inca.local/files/ /media/document/dialogos em saude publica 2018 co mpleto ok 0.pdf. Acesso em 03 mar. 2020.

GURJÃO, Fernanda Maia; MAIA, Lúcia de Fátima Rocha Bezerra; CARVALHO, Maria de Fátima Sousa Lima. Tratamento Fora De Domicílio: perspectivas dos pacientes do transplante renal de um hospital universitário. Revista Serv. Soc. \& Saúde, Campinas, SP, v. 17, n.1 [25], p 155-180, jan./jun., 2018. Disponível em: https://periodicos.sbu.unicamp.br/ojs/index.php/sss/arti cle/view/8655206. Acesso em 03 mar. 2020.

VIEIRA, Ana claudia Dias; NOGUEIRA, Maria Aparecida Nery Da Silva. $O$ programa de tratamento fora de domicílio TFD e os desafios para o acesso pelos usuários do SUS 
numa perspectiva de direito. III Congresso de Serviço Social do IMIP, 2017.

VIEGAS, Anna Paula Bise. CARMO, Rose Ferraz. LUZ, Zélia Maria Profeta da. Fatores que influenciam o acesso aos serviços de saúde na visão de profissionais e usuários de uma unidade básica de referência. Revista Saúde e Sociedade. São Paulo, v.24, n.1, p.100-112, 2015. Disponível em: https://www.scielo.br/pdf/sausoc/v24n1/0104-1290sausoc-24-1-0100.pdf. Acesso em 16 ago. 2020.

Submissão: 05/06/2020

Aprovado para publicação: 15/09/2020 